(6) OPEN ACCESS

${ }^{1}$ Institute of Child Health, Great Ormond Street Hospital, London, UK

${ }^{2}$ Department of Paediatrics, Norfolk and Norwich University Hospital, Norwich, UK ${ }^{3}$ Department of Paediatric Gastroenterology, Royal Hospital for Children, Glasgow,

${ }^{4}$ Centre for Paediatric Gastroenterology, Royal Free Hospital, London, UK ${ }^{5}$ Department of Paediatric Gastroenterology, John Radcliffe Hospital, Oxford, UK

\section{Correspondence to}

Dr Richard K Russell,

Department of Paediatric Gastroenterology, The Royal Hospital for Children, 1345 Govan Road, Glasgow G51 4TF, UK; richardrussell@nhs.net

Received 1 June 2015 Revised 9 October 2015 Accepted 12 October 2015 Published Online First 9 November 2015

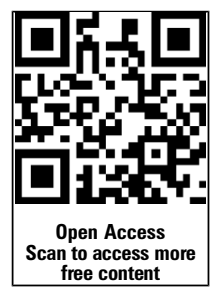

\section{SLinked}

- http://dx.doi.org/10.1136/ archdischild-2014-307218

\section{CrossMark}

To cite: Kammermeier J, Morris M-A, Garrick V, et al. Arch Dis Child

2016:101:475-480.

\title{
Management of Crohn's disease
}

\author{
Jochen Kammermeier, ${ }^{1}$ Mary-Anne Morris, ${ }^{2}$ Vikki Garrick, ${ }^{3}$ Mark Furman, ${ }^{4}$ \\ Astor Rodrigues, ${ }^{5}$ Richard K Russell, ${ }^{3}$ BSPGHAN IBD Working Group
}

\begin{abstract}
Crohn's disease $(C D)$ is rapidly increasing in children so an up to date knowledge of diagnosis, investigation and management is essential. Exclusive enteral nutrition is the first line treatment for active disease. The vast majority of children will need immunosuppressant treatment and around $20 \%$ will need treatment with biologics. Recent guidelines have helped make best use of available therapies.
\end{abstract}

\section{INTRODUCTION}

Crohn's disease (CD) is a chronic inflammatory disorder, which can affect any part of the intestinal tract as well as extraintestinal tissue. Factors that contribute towards the pathogenesis of the disease are the host's genetic profile, immune system and environmental factors such as the gut microbiota. ${ }^{1}$

CD occurs in all ages with recently reported paediatric figures from Scotland and South England suggesting an incidence of 4.75 and 5.85/100 000 people, respectively. ${ }^{2}{ }^{3}$ UK prevalence data are limited, but suggest a figure of 32 per 100000 people. $^{4}$ Due to yet undefined environmental factors, the incidence and prevalence of $\mathrm{CD}$ is rising, in both adult and paediatric studies. ${ }^{5} 6$

In this review, we aimed to update important new developments in the management of $\mathrm{CD}$ for paediatricians in the UK highlighting the key publications and guidelines published recently. ${ }^{7}$ We also recognise that the BSPGHAN inflammatory bowel disease (IBD) guidelines published previously, now contain many recommendations that needed updated guidance, but without generation of a specifically new guideline. ${ }^{8} 9$

\section{Diagnosis}

Key clinical symptoms of CD comprise diarrhoea, abdominal pain, growth failure and rectal bleeding with the first three being the most common in patients first presenting with $\mathrm{CD} .{ }^{10} \mathrm{CD}$ often has an insidious onset, which may contribute to considerable diagnostic delay. $\mathrm{CD}$ can affect the entire intestinal tract, and transmural inflammation can lead to stricture formation and fistulisation between the gut and other abdominal organs as well as the skin. ${ }^{11}$ Perianal inspection is imperative as significant perianal involvement (eg, inflamed fissures or skin tags, abscesses and fistulae) are seen at presentation in at least $15 \%$ of children with $\mathrm{CD}^{12}$ (see figure 1). Extraintestinal manifestations in IBD can affect the skin, eyes, musculoskeletal and hepatobiliary systems. ${ }^{13}$

Once IBD is suspected, patients should be fast tracked to specialist services (for relevant blood and stool tests see Fell et $a l^{13 a}$ and figure 2). The revised Porto criteria provide detailed guidance on the diagnostic evaluation of paediatric patients with $\mathrm{IBD}^{10}$ emphasising the necessity to perform upper gastrointestinal endoscopy and ileocolonoscopy with histology as well as small bowel imaging (see figure 1). ${ }^{14}$

Once CD has been established, ongoing disease activity is monitored by clinical review and assessment. The originally reported Paediatric Crohn's Disease Activity Index (PCDAI) ${ }^{15}$ is now mostly superseded by the weighted PCDAI which takes clinical symptoms, laboratory markers, anthropometric data and clinical examination into account (table 1). ${ }^{16}$ This is an assessment, which can be used by all paediatricians to objectively assess disease activity.

\section{TREATMENT STRATEGY}

Treatment aims are to induce and maintain clinical remission, optimise nutrition, define bone status, optimise growth and pubertal progress and minimise drug adverse effects. Treatment beyond simple symptom resolution is now commonly employed with intestinal/mucosal healing the target of contemporary $\mathrm{CD}$ care. $^{17}$

The strategy of early introduction of immunomodulatory and biological therapies to induce deep remission (long-term intestinal healing without relapse) particularly in high-risk patients (severe endoscopic or perianal disease, poor response to induction therapy, extensive, stricturing or penetrating disease, marked growth retardation and/or severe osteoporosis) might change the natural history of the disease and is being increasingly used in paediatric IBD.

\section{INDUCTION OF REMISSION}

\section{Exclusive enteral nutrition}

Exclusive enteral nutrition (EEN) for 6-8 weeks, using a whole protein formula is the first-line therapy to induce remission in children with active $\mathrm{CD}^{7}$ Clinical response rates are approximately $80 \%$ and similar to corticosteroids. ${ }^{18}{ }^{19}$ However, in contrast to corticosteroids, EEN offers significant nutritional advantages and provides superior mucosal healing in comparison to steroids. ${ }^{20}{ }^{21}$ Clinical improvement usually occurs within days and alternative therapy should be considered in the absence of response within 2-4 weeks. No differences between polymeric (whole protein) and elemental (amino acid) formulae have been shown. ${ }^{22} 23$ Polymeric feeds are the preferred option as they are better tolerated, more costeffective and require less nasogastric feeding. ${ }^{24}$

Success with EEN is maximised by robust and frequent patient and family support from the multidisciplinary team (MDT), particularly in the early stages of treatment. Clinical review halfway 

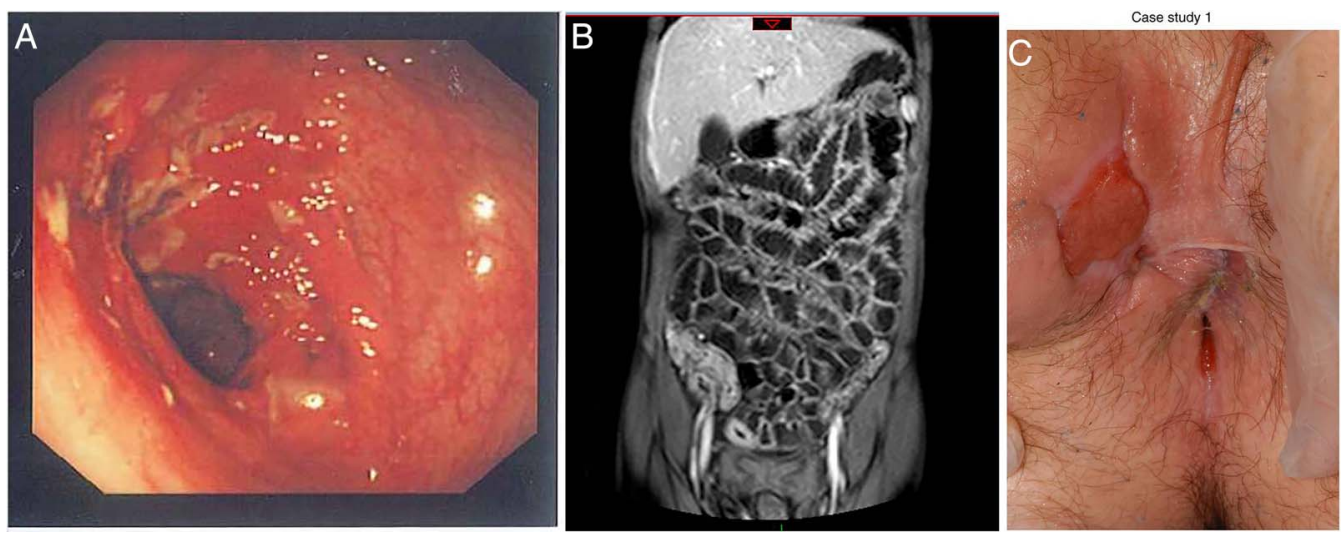

Figure 1 (A) Left: endoscopic view of the transverse colon in Crohn's disease (CD) revealing a cluster of deep ulcers. (B) Centre: magnetic resonance enterography showing extensive terminal ileal disease. (C) Right: perianal disease (inflamed skin tag and external orifice of a fistula at 10:00) in CD patient (reproduced with permission).

through therapy further facilitates completion of the full course. ${ }^{25}$ Limited data suggest that ongoing maintenance enteral nutrition can be a useful strategy in some children after the course of exclusive enteral nutrition is complete. ${ }^{26}$

\section{Corticosteroids}

Corticosteroids can be used to induce remission in CD, if EEN is not possible or the patient does not respond to therapy. Prednisolone is given orally $(1 \mathrm{mg} / \mathrm{kg}$, maximum: $40 \mathrm{mg} / \mathrm{day}$, tapering over $8-10$ weeks) for moderate/severe active luminal CD. For mild/moderate ileocaecal disease, budesonide is an alternative option with fewer steroid-related side effects (maximum: $12 \mathrm{mg} /$ day, tapering over 2-4 weeks). Intravenous steroids (preferred intravenous steroid: methylprednisolone at $1-1.5 \mathrm{mg} / \mathrm{kg}$, maximum: $60 \mathrm{mg} /$ day; or alternatively: hydrocortisone $2-4 \mathrm{mg} / \mathrm{kg} /$ dose, maximum $100 \mathrm{mg} /$ dose four times a day) may be initially needed for severe disease.

Similar to EEN, clinical remission rates of up to $80 \%$ have been reported, but with considerably lower mucosal healing rates. ${ }^{27} 28$ Adverse effects are proportional to dose and duration, and include adrenal suppression, growth failure, cosmetic and behavioural effects.

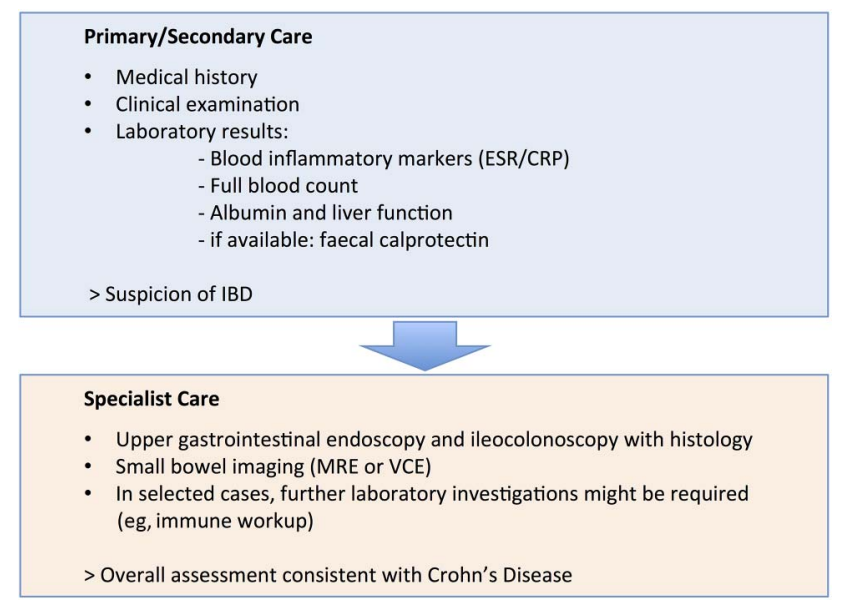

Figure 2 Diagnostic pathways in Crohn's disease (CD). Patients displaying features, consistent with $C D$ should be fast tracked for specialist review. IBD, inflammatory bowel disease; MRE, magnetic resonance enterography; VCE, video capsule endoscopy.
Anti-tumour necrosis factor $\boldsymbol{\alpha}$ antibodies

Anti-tumour necrosis factor (TNF) therapy is also recognised as induction therapy for selected patients with moderate to severe disease. These therapies will be discussed in detail in the Maintenance of remission section.

\section{Antibiotics}

Adult studies demonstrating reduced fistula drainage support the use of antibiotics (metronidazole and/or ciprofloxacin) in perianal fistulising CD disease. ${ }^{29}$ Limited paediatric data on combination treatment with azithromycin and metronidazole in luminal disease have been encouraging, but await validation in larger better designed clinical trials. ${ }^{30}$

\section{MAINTENANCE OF REMISSION \\ Thiopurines}

Results from paediatric and adult studies support the use of thiopurines (6-mercaptopurine or azathioprine) to maintain disease remission. ${ }^{27}{ }^{31}$ At 18 months, cumulative steroid doses and relapse rates were significantly lower in children on 6-mercaptopurine compared with placebo ( $9 \%$ vs $47 \%)$. In addition, a reduced need for surgery in $\mathrm{CD}$ was reported in patients on azathioprine. ${ }^{32}$ These benefits need to be balanced against the side effects and long-term risks of immunosuppressant therapy. ${ }^{33}$ For detailed management of azathioprine see Fell et al. ${ }^{13 a}$

\section{Methotrexate}

Paediatric retrospective cohort studies report 50\%-80\% effectiveness of methotrexate (MTX) in children who failed to respond or were intolerant to thiopurine therapy in maintaining remission. ${ }^{34} 35$

MTX $\left(15 \mathrm{mg} / \mathrm{m}^{2}\right.$ one time per week, maximum: $25 \mathrm{mg}$ subcutaneously) in conjunction with folate supplementation is an alternative option as primary maintenance therapy or following thiopurine failure or intolerance. ${ }^{7}$

MTX is particularly suitable as first-line treatment in patients who have coexistent inflammatory arthritis. ${ }^{36}$ Data on oral bioavailability are variable, but the latest evidence suggests that initiating treatment subcutaneously followed by administering the drug orally can be an alternative to long-term subcutaneous administration. ${ }^{37}$ Adverse events include flu-like symptoms, transaminitis and infrequently myelosuppression, which may require dosage adjustment or drug withdrawal. Significant 
Table 1 The weighted Paediatric Crohn's Disease Activity Index ${ }^{16}$

\begin{tabular}{|c|c|c|c|}
\hline & & & Score \\
\hline \multicolumn{4}{|l|}{ History (recall, 1 week) } \\
\hline \multicolumn{4}{|l|}{ Abdominal pain } \\
\hline $0=$ none & $10=$ mild: brief, does not interfere with activities & $\begin{array}{l}20=\text { moderate/severe: daily, longer lasting, affects } \\
\text { activities, nocturnal }\end{array}$ & \\
\hline \multicolumn{4}{|l|}{ Patient functioning, general well-being } \\
\hline $0=$ no limitation of activities, well & $\begin{array}{l}10=0 c c a s i o n a l \text { difficulty in maintaining age appropriate } \\
\text { activities, below par }\end{array}$ & $20=$ frequent limitation of activity, very poor & \\
\hline \multicolumn{4}{|l|}{ Stools (per day) } \\
\hline $0=0-1$ liquid stools, no blood & $7.5=$ up to 2 semiformed with small blood, or 2-5 liquid & $15=$ gross bleeding, or $\geq 6$ liquid or nocturnal diarrhoea & \\
\hline \multicolumn{4}{|l|}{ Laboratory } \\
\hline \multicolumn{4}{|l|}{ Erythrocyte sedimentation rate } \\
\hline $0 \leq 20 \mathrm{~mm} / \mathrm{h}$ & $7.5=20-50 \mathrm{~mm} / \mathrm{h}$ & $15 \geq 50 \mathrm{~mm} / \mathrm{h}$ & \\
\hline \multicolumn{4}{|l|}{ Albumin } \\
\hline $0 \geq 3.5 \mathrm{~g} / \mathrm{dL}$ & $10=3.1-3.4 \mathrm{~g} / \mathrm{dL}$ & $20 \leq 3.0 \mathrm{~g} / \mathrm{dL}$ & \\
\hline \multicolumn{4}{|l|}{ Examination } \\
\hline \multicolumn{4}{|l|}{ Weight } \\
\hline $\begin{array}{l}0=\text { weight gain or voluntary weight } \\
\text { stable/loss }\end{array}$ & $5=$ involuntary weight stable, weight loss $1 \%-9 \%$ & $10=$ weight loss $\geq 10 \%$ & \\
\hline \multicolumn{4}{|l|}{ Perianal disease } \\
\hline $0=$ none, asymptomatic tags & 7.5=1-2 indolent fistula, scant drainage, no tenderness & $15=$ active fistula, drainage, tenderness or abscess & \\
\hline \multicolumn{4}{|l|}{ Extraintestinal manifestations } \\
\hline \multicolumn{4}{|c|}{ fever $\geq 38.5^{\circ} \mathrm{C}$ for 3 days over last week, definite arthritis, uveitis, erythema nodosum and pyoderma gangrenosum } \\
\hline $0=$ none & & $10=$ one or more & \\
\hline Total score (0-125) & & & \\
\hline
\end{tabular}

hepatocellular liver disease is rare. Nausea and vomiting have been reported in 11\%-24\% of patients, and can be successfully controlled with antiemetic medication in many but not all patients. ${ }^{38}$ Contraception is essential. Teaching patients and families to deliver the drug in the home setting is achievable for the majority, allowing flexibility in drug delivery, increasing drug acceptability while reducing overall cost. ${ }^{39}$

\section{Anti-TNF $\alpha$ antibodies}

Prior to commencing anti-TNF therapy (chimeric monoclonal antibody: infliximab; or humanised monoclonal antibody: adalimumab), patients have to be screened for tuberculosis and hepatitis B to prevent reactivation. Varicella immunity should also be established and in seronegative cases, and if feasible, varicella zoster immunisation should be considered before treatment.

Anti-TNF treatment is recommended for inducing and maintaining remission in children with steroid refractory disease or $\mathrm{CD}$ affecting the gut lumen (luminal disease) despite optimised immunomodulation. Anti-TNF therapy is also used by some clinicians as primary induction therapy in active perianal disease and in patients at risk of poor outcomes, but both indications are currently outside of the drugs licence. ${ }^{\text {? }}$

In luminal disease, infliximab response rates of up to $90 \%$ and remission rates at 1 year of $55 \%-60 \%$ have been reported. ${ }^{4041}$ Infliximab improved outcomes of perianal CD with response rates of $75 \%$ and remission rates of $50 \%$ at 1 year. ${ }^{42}$ Adalimumab achieved 1 -year remission rates of $45 \%$ in anti-TNF $\alpha$ antibody naïve children and $20 \%$ in infliximab non-responders. ${ }^{43}$

Infliximab is first administered intravenously in doses of $5 \mathrm{mg} / \mathrm{kg}$ at weeks zero, two and six followed by 8 -weekly infusions. Adalimumab is administered subcutaneously on alternate weeks (most commonly $40 \mathrm{mg}$ ) after initial loading dose(s) of 80 or $160 \mathrm{mg}$.
The proportion of primary anti-TNF non-responders (failure to respond after induction course of 6 weeks) in paediatric CD is low (10\%-25\%). However, more commonly antibody formation against the drug over time can result in secondary loss of response. $^{44}$ The formation of antibodies and the resulting loss of response are reduced by the use of co-immunosuppression with either thiopurines or MTX. ${ }^{33}$ As such the strategy of combination therapy is commonly employed in the UK, but this needs to be continuously balanced against the increased side effect profile of this strategy. Recently, infliximab drug and antibody levels have become available to support decision making in partial or complete lack/loss of treatment response. ${ }^{46}{ }^{47}$ If antibody and drug trough levels are inadequate, dose escalation and/or interval reduction can regain response. ${ }^{7}$

Adverse effects following anti-TNF therapy include acute infusion reactions (up to 15\%), delayed hypersensitivity reactions (8\%), skin eruptions (eczema/psoriasis, 8\%) and serious infections (3.3\%) including reactivation of latent tuberculosis. ${ }^{48}$

\section{Other treatments}

Inducing remission with aminosalicylates may be considered rarely in mild colonic CD in a small subset of patients only. The evidence for other immunomodulators is not as extensive as for thiopurines and MTX, but thalidomide, sirolimus and tacrolimus can be useful in selected patients' dependant on individual circumstances. $^{49-51}$

\section{Surgery in $C D$}

The risk of requiring surgery within 5 years of diagnosis in paediatric CD is around $20 \% .^{52}$ In one retrospective study, out of 69 patients who required surgery, 58\% underwent right hemi-colectomy, $3 \%$ subtotal colectomy, $12 \%$ stoma formation and $14 \%$ surgery for perianal disease. ${ }^{53}$ 
Patients with late-onset paediatric, severe/extensive or stricturing/penetrating $\mathrm{CD}$ have increased the risk for bowel surgery. Emergency surgical interventions are indicated in circumstances such as severe haemorrhage, intestinal perforation and toxic megacolon.

Otherwise, surgery is commonly carried out in three scenarios: isolated/localised disease including perianal disease, IBD refractory to conventional medical therapy and when complications arise such as strictures and fistulae. ${ }^{53}$ Resectional surgery is increasingly being carried out laparoscopically.

In cases where CD is limited to an isolated bowel segment (eg, ileocaecal CD), surgery might establish a postoperative recurrence-free interval to allow for growth and development. ${ }^{55}$

Bowel rest through temporary diversion ileostomy has been considered in patients with extensive colonic and/or perianal disease refractory to medical treatment. Treatment of perianal fistulising CD with anti-TNF therapy is effective and significantly reduces the need for surgery. ${ }^{56}$ Combined medical and surgical treatment within the MDT is regarded by many as the best treatment approach to complex perianal disease. ${ }^{57}$ Enteroenteric fistulae may respond to anti-TNF therapy, but are more likely to require surgical intervention. Perianal fistulae can be transsphincteric, intersphincteric, suprasphincteric, extrasphincteric or subanodermal. Fistulae management requires an individualised approach considering surgical and medical options. Surgical fistulotomy in patients with a simple, symptomatic fistula is considered appropriate. Surgery in complex fistulae bares a high risk of sphincter damage and faecal incontinence. ${ }^{58} 59$ Insertion of loose, ie non-cutting seton sutures after incision and drainage can facilitate better long-term healing, and prevention of recurrence of abscesses in selected patients with perianal disease. ${ }^{59}$

Strictures particularly involving the terminal ileum/ileocaecal valve are a common indication for CD surgery. ${ }^{52}$ Limited resections or stricturoplasty are considered best practice to preserve gut length and prevent short bowel syndrome.

\section{GENERAL CONSIDERATIONS}

\section{IBD and cancer}

The overall risk to develop malignancies such as lymphomas for children with IBD is low, but higher than the general paediatric population. In one large cohort study of paediatric IBD patients, two lymphomas were diagnosed in a 30 -year period (the risk of developing lymphoma on thiopurines was found to be approximately eightfold higher when compared with the general population). ${ }^{60}$ Over 30 cases of hepatosplenic T-cell lymphoma, which is associated with very high mortality and mainly affects young men, have been reported in IBD patients. The majority $(56 \%)$ were treated with anti-TNF-thiopurine combination therapy. ${ }^{61}$ Mortality overall is very rare in paediatric IBD and usually is secondary to infection or cancer. ${ }^{62}$

\section{Vaccination}

Live vaccination (eg, varicella) should be considered in immune competent IBD patients prior to long-term immunosuppression. The annual inactivated influenza vaccination should be offered to all children with IBD too. ${ }^{63}$

\section{Education}

Children and their parents should be encouraged to engage with national and international patients' IBD forums such as CICRA ('Crohn's in Childhood Research Association') (http://www. cicra.org) and 'Crohn's and Colitis UK' (http://www. crohnsandcolitis.org.uk).

\section{Multidisciplinary team}

National standards dictate that children and young people with IBD are managed, at least in part, by a Paediatric Gastroenterology team including medical, nursing and dietetic staff. $^{64}{ }^{65}$ In this age group, disease control and maintaining patient engagement can be challenging and appropriate support to the patient and carers is vital.

\section{Transition}

Transition to adult services is a particularly challenging time for the patient and family. It is best done as a staged process over months to years dependent on the physical, psychological and emotional state of the young person and should prepare them for managing their consultation independently. ${ }^{66} 67$ Continuity and consistency are recommended to encourage engagement in transition, and the clinical nurse specialist working within the MDT often fulfils this role in addition to coordinating the process.

\section{Compliance}

Non-adherence to medical therapies is common in chronic disease management and can be further exacerbated during adolescence. ${ }^{68}{ }^{69}$ Knowledge of medication does not necessarily equate to compliance and forgetting, lack of time, no perceived benefit and too many tablets are common themes in patients with IBD and other conditions. Consultations with the child or young person should focus on devising practical and realistic management plans. 'Safety netting' (agreeing a clear plan for what to do if symptoms do not resolve following treatment), ${ }^{70}$ can empower and support the young person in managing their IBD.

\section{CONCLUSION}

The management of paediatric CD has evolved significantly over recent years with evidence-based guidelines now in place to assist day-to-day practice. Novel tools for personalised IBD management (drug metabolites, anti-TNF antibodies, stool inflammatory markers) provide a better understanding of the patients' disease status. The pathophysiology of CD remains relatively poorly understood, but advances in molecular technologies are likely to facilitate a deeper understanding of pathways involved in IBD pathogenesis, and will hopefully reveal novel disease biomarkers and treatment strategies.

Correction notice This paper has been amended since it was published Online First. The names of the collaborators have now been added.

Acknowledgements We acknowledge the important contributions made by the other members of the BSPGHAN IBD Working Group in paper conceptualisation, content generation and approval of the final manuscript.

Collaborators John M Fell, Rafeeq Muhammed, Christine Spray, Kay Crooke, Su Bunn and Marcus Auth.

Contributors All members of the BSPGHAN IBD Working Group have participated in paper conceptualisation, content generation and approval of the final manuscript, and are either listed as named authors or collaborators dependent on the relative contribution to the manuscript.

Funding RKR has received support from a Medical Research Council (MRC) patient research cohorts initiative grant (G0800675) for PICTS. RKR is supported by an NHS Research Scotland career fellowship award. The work of the IBD team at Yorkhill is supported by the Catherine McEwan Foundation and the Yorkhill IBD fund.

Competing interests RKR has received speaker's fees, travel support or participated in medical board meetings with MSD immunology, Abbott, Dr Falk, Nestle, Janssen, NAPP and Ferring Pharmaceuticals. VG has received speaker's fees from MSD.

Provenance and peer review Commissioned; externally peer reviewed. 
Open Access This is an Open Access article distributed in accordance with the terms of the Creative Commons Attribution (CC BY 4.0) license, which permits others to distribute, remix, adapt and build upon this work, for commercial use, provided the original work is properly cited. See: http://creativecommons.org/ licenses/by/4.0/

\section{REFERENCES}

1 Maloy KJ, Powrie F. Intestinal homeostasis and its breakdown in inflammatory bowel disease. Nature 2011;474:298-306.

2 Ashton JJ, Wiskin AE, Ennis $S$, et al. Rising incidence of paediatric inflammatory bowel disease (PIBD) in Wessex, Southern England. Arch Dis Child 2014;99:659-64.

3 Henderson P, Hansen R, Cameron FL, et al. Rising incidence of pediatric inflammatory bowel disease in Scotland. Inflamm Bowel Dis 2012;18:999-1005.

4 Henderson P, Rogers P, Gillett PM, et al. The epidemiology and natural history of paediatric inflammatory bowel disease in a UK region: a prospective 14-year study. Arch Dis Child 2012;97(Suppl 1):A53-A54.

5 Molodecky NA, Soon IS, Rabi DM, et al. Increasing incidence and prevalence of the inflammatory bowel diseases with time, based on systematic review. Gastroenterology 2012;142:46-54.

6 Benchimol El, Fortinsky KJ, Gozdyra P, et al. Epidemiology of pediatric inflammatory bowel disease: a systematic review of international trends. Inflamm Bowel Dis 2011;17:423-39

7 Ruemmele FM, Veres G, Kolho KL, et al. Consensus guidelines of ECCO/ESPGHAN on the medical management of pediatric Crohn's disease. J Crohns Colitis 2014;8:1179-207.

8 Sandhu BK, Fell JM, Beattie RM, et al. Guidelines for the management of inflammatory bowel disease in children in the United Kingdom. J Pediatr Gastroenterol Nutr 2010;50(Suppl 1):S1-13.

9 Wilson DC, Thomas AG, Croft NM, et al. Systematic review of the evidence base for the medical treatment of paediatric inflammatory bowel disease. J Pediatr Gastroenterol Nutr 2010;50(Suppl 1):S14-34.

10 Levine A, Koletzko S, Turner D, et al. ESPGHAN revised porto criteria for the diagnosis of inflammatory bowel disease in children and adolescents. J Pediatr Gastroenterol Nutr 2014:58:795-806.

11 Van Limbergen J, Russell RK, Drummond HE, et al. Definition of phenotypic characteristics of childhood-onset inflammatory bowel disease. Gastroenterology 2008; 135:1114-22

12 Keljo DJ, Markowitz J, Langton C, et al. Course and treatment of perianal disease in children newly diagnosed with Crohn's disease. Inflamm Bowel Dis 2009;15:383-7.

13 Jose FA, Garnett EA, Vittinghoff E, et al. Development of extraintestinal manifestations in pediatric patients with inflammatory bowel disease. Inflamm Bowel Dis 2009;15:63-8.

13a Fell JM, Muhammed R, Spray C, et al. Management of ulcerative colitis. Arch Dis Child 2016;101:469-74.

14 Henderson P, Anderson NH, Wilson DC. The diagnostic accuracy of fecal calprotectin during the investigation of suspected pediatric inflammatory bowel disease: a systematic review and meta-analysis. Am J Gastroenterol 2014;109:637-45.

15 Hyams JS, Ferry GD, Mandel FS, et al. Development and validation of a pediatric Crohn's disease activity index. J Pediatr Gastroenterol Nutr 1991;12:439-47.

16 Turner D, Griffiths AM, Walters TD, et al. Mathematical weighting of the pediatric Crohn's disease activity index (PCDAI) and comparison with its other short versions. Inflamm Bowel Dis 2012;18:55-62.

17 Ruemmele FM, Hyams JS, Otley A, et al. Outcome measures for clinical trials in paediatric IBD: an evidence-based, expert-driven practical statement paper of the paediatric ECCO committee. Gut 2015;64:438-46.

18 Dziechciarz P, Horvath A, Shamir R, et al. Meta-analysis: enteral nutrition in active Crohn's disease in children. Aliment Pharmacol Ther 2007;26:795-806.

19 Heuschkel RB, Menache CC, Megerian JT, et al. Enteral nutrition and corticosteroids in the treatment of acute Crohn's disease in children. J Pediatr Gastroenterol Nutr 2000;31:8-15.

20 Borrelli 0 , Cordischi L, Cirulli M, et al. Polymeric diet alone versus corticosteroids in the treatment of active pediatric Crohn's disease: a randomized controlled open-label trial. Clin Gastroenterol Hepatol 2006;4:744-53.

21 Fell JM, Paintin M, Arnaud-Battandier F, et al. Mucosal healing and a fall in mucosal pro-inflammatory cytokine mRNA induced by a specific oral polymeric diet in paediatric Crohn's disease. Aliment Pharmacol Ther 2000;14:281-9.

22 Verma S, Brown S, Kirkwood B, et al. Polymeric versus elemental diet as primary treatment in active Crohn's disease: a randomized, double-blind trial. Am J Gastroenterol 2000;95:735-9.

23 Ludvigsson JF, Krantz M, Bodin L, et al. Elemental versus polymeric enteral nutrition in paediatric Crohn's disease: a multicentre randomized controlled trial. Acta Paediatrica 2004;93:327-35.

24 Rodrigues AF, Johnson T, Davies $\mathrm{P}$, et al. Does polymeric formula improve adherence to liquid diet therapy in children with active Crohn's disease? Arch Dis Child 2007;92:767-70.
25 Garrick V, Buchanan E, Bishop J, et al. Specialist nurse and dietitian care pathway for exclusive enteral nutrition in paediatric Crohn's Disease-a tertiary experience. J Pediatr Gastroenterol Nutr 2011;52(suppl 2): E2.

26 Duncan $\mathrm{H}$, Buchanan $\mathrm{E}$, Cardigan $\mathrm{T}$, et al. A retrospective study showing maintenance treatment options for paediatric $C D$ in the first year following diagnosis after induction of remission with EEN: supplemental enteral nutrition is better than nothing! BMC Gastroenterol 2014;14:50.

27 Markowitz J, Grancher K, Kohn N, et al. A multicenter trial of 6-mercaptopurine and prednisone in children with newly diagnosed Crohn's disease. Gastroenterology 2000;119:895-902.

28 Levine A, Weizman Z, Broide $E$, et al. A comparison of budesonide and prednisone for the treatment of active pediatric Crohn disease. J Pediatr Gastroenterol Nutr 2003;36:248-52.

29 Khan KJ, Ullman TA, Ford AC, et al. Antibiotic therapy in inflammatory bowel disease: a systematic review and meta-analysis. Am J Gastroenterol 2011;106:661-73.

30 Levine A, Turner D. Combined azithromycin and metronidazole therapy is effective in inducing remission in pediatric Crohn's disease. J Crohns Colitis 2011;5:222-6.

31 Prefontaine E, Sutherland LR, Macdonald JK, et al. Azathioprine or 6-mercaptopurine for maintenance of remission in Crohn's disease. Cochrane Database Syst Rev 2009;(1):CD000067.

32 Chatu S, Subramanian V, Saxena S, et al. The role of thiopurines in reducing the need for surgical resection in Crohn's disease: a systematic review and meta-analysis. Am J Gastroenterol 2014;109:23-34.

33 Cozijnsen MA, Escher JC, Griffiths A, et al. Benefits and risks of combining anti-tumor necrosis factor with immunomodulator therapy in pediatric inflammatory bowel disease. Inflamm Bowel Dis 2015;21:951-61.

34 Weiss B, Lerner A, Shapiro R, et al. Methotrexate treatment in pediatric Crohn disease patients intolerant or resistant to purine analogues. J Pediatr Gastroenterol Nutr 2009;48:526-30

35 Willot $\mathrm{S}$, Noble A, Deslandres C. Methotrexate in the treatment of inflammatory bowel disease: an 8-year retrospective study in a Canadian pediatric IBD center. Inflamm Bowel Dis 2011;17:2521-6.

36 Lopez-Olivo MA, Siddhanamatha HR, Shea B, et al. Methotrexate for treating rheumatoid arthritis. Cochrane Database Syst Rev 2014;6:CD000957.

37 Turner D, Doveh E, Cohen A, et al. Efficacy of oral methotrexate in paediatric Crohn's disease: a multicentre propensity score study. Gut 2015;64:1898-904.

38 Kempinska A, Benchimol El, Mack A, et al. Short-course ondansetron for the prevention of methotrexate-induced nausea in children with Crohn disease. J Pediatr Gastroenterol Nutr 2011;53:389-93.

39 Garrick V, Atwal P, Barclay AR, et al. Successful implementation of a nurse-led teaching programme to independently administer subcutaneous methotrexate in the community setting to children with Crohn's disease. Aliment Pharmacol Ther 2009;29:90-6.

40 Hyams J, Crandall W, Kugathasan $S$, et al. Induction and maintenance infliximab therapy for the treatment of moderate-to-severe Crohn's disease in children. Gastroenterology 2007:132:863-73.

41 Ruemmele FM, Lachaux A, Cézard JP, et al. Efficacy of infliximab in pediatric Crohn's disease: a randomized multicenter open-label trial comparing scheduled to on demand maintenance therapy. Inflamm Bowel Dis 2009;15:388-94.

42 Dupont-Lucas C, Dabadie A, Alberti C, et al. Predictors of response to infliximab in paediatric perianal Crohn's disease. Aliment Pharmacol Ther 2014;40:917-29.

43 Hyams JS, Griffiths A, Markowitz J, et al. Safety and efficacy of adalimumab for moderate to severe Crohn's disease in children. Gastroenterology 2012;143:365-74.

44 Cameron FL, Wilson ML, Basheer N, et al. Anti-TNF therapy for paediatric IBD: the Scottish national experience. Arch Dis Child 2015;100:399-405.

45 Feagan BG, McDonald JW, Panaccione R, et al. Methotrexate in combination with infliximab is no more effective than infliximab alone in patients with Crohn's disease. Gastroenterology 2014;146:681-8.

46 Ungar B, Chowers Y, Yavzori M, et al. The temporal evolution of antidrug antibodies in patients with inflammatory bowel disease treated with infliximab. Gut 2014;63:1258-64.

47 Ben-Horin $\mathrm{S}$, Waterman $\mathrm{M}$, Kopylov $\mathrm{U}$, et al. Addition of an immunomodulator to infliximab therapy eliminates antidrug antibodies in serum and restores clinical response of patients with inflammatory bowel disease. Clin Gastroenterol Hepatol 2013:11:444-7.

48 de Bie $\mathrm{Cl}$, Escher JC, de Ridder L. Antitumor necrosis factor treatment for pediatric inflammatory bowel disease. Inflamm Bowel Dis 2012;18:985-1002.

49 McSharry K, Dalzell AM, Leiper K, et al. Systematic review: the role of tacrolimus in the management of Crohn's disease. Aliment Pharmacol Ther 2011;34:1282-94.

50 Mutalib M, Borrelli O, Blackstock S, et al. The use of sirolimus (rapamycin) in the management of refractory inflammatory bowel disease in children. I Crohns Colitis 2014;8:1730-4.

51 Lazzerini M, Martelossi S, Magazzù G, et al. Effect of thalidomide on clinical remission in children and adolescents with refractory Crohn disease: a randomized clinical trial. JAMA 2013;310:2164-73. 
52 Schaefer ME, Machan JT, Kawatu D, et al. Factors that determine risk for surgery in pediatric patients with Crohn's disease. Clin Gastroenterol Hepatol 2010;8:789-94.

53 Blackburn SC, Wiskin AE, Barnes C, et al. Surgery for children with Crohn's disease: indications, complications and outcome. Arch Dis Child 2014;99:420-6.

54 Hwang JM, Varma MG. Surgery for inflammatory bowel disease. World J Gastroenterol 2008;14:2678-90.

55 Pacilli $\mathrm{M}$, Eaton $\mathrm{S}$, Fell JM, et al. Surgery in children with Crohn disease refractory to medical therapy. J Pediatr Gastroenterol Nutr 2011;52:286-90.

56 Duff S, Sagar PM, Rao M, et al. Infliximab and surgical treatment of complex anal Crohn's disease. Colorectal Dis 2012;14:972-6.

57 Garrick V, Stenhouse E, Haddock G, et al. A multidisciplinary team model of caring for patients with perianal Crohn's disease incorporating a literature review, topical therapy and personal practice. Frontline Gastroenterol 2013;4:152-60.

58 Chung W, Ko D, Sun C, et al. Outcomes of anal fistula surgery in patients with inflammatory bowel disease. Am J Surg 2010;199:609-13.

59 Geltzeiler $\mathrm{CB}$, Wieghard N, Tsikitis VL. Recent developments in the surgical management of perianal fistula for Crohn's disease. Ann Gastroenterol 2014;27:320-30.

60 Ashworth LA, Billett A, Mitchell P, et al. Lymphoma risk in children and young adults with inflammatory bowel disease: analysis of a large single-center cohort. Inflamm Bowel Dis 2012;18:838-43.

61 Kotlyar DS, Osterman MT, Diamond RH, et al. A systematic review of factors that contribute to hepatosplenic T-cell lymphoma in patients with inflammatory bowel disease. Clin Gastroenterol Hepatol 2011;9:36-41.
62 de Ridder L, Turner D, Wilson DC, et al. Malignancy and mortality in pediatric patients with inflammatory bowel disease: a multinational study from the Porto pediatric IBD group. Inflamm Bowel Dis 2014;20:291-300.

63 Veereman-Wauters $G$, de Ridder L, Veres $G$, et al. Risk of infection and prevention in pediatric patients with IBD: ESPGHAN IBD Porto Group commentary. J Pediatr Gastroenterol Nutr 2012;54:830-7.

64 Mowat C, Cole A, Windsor A, et al. Guidelines for the management of inflammatory bowel disease in adults. Gut 2011;60:571-607.

65 Group TIS. Standards for the healthcare of people who have Inflammatory Bowel Disease (IBD). 2013. Published by Oyster Healthcare Communications Ltd on behalf of the IBD Standards Group.

66 Goodhand J, Dawson R, Hefferon M, et al. Inflammatory bowel disease in young people: the case for transitional clinics. Inflamm Bowel Dis 2010;16: 947-52.

67 Leung Y, Heyman MB, Mahadevan U. Transitioning the adolescent inflammatory bowel disease patient: guidelines for the adult and pediatric gastroenterologist. Inflamm Bowel Dis 2011;17:2169-73.

68 Kripalani S, Yao X, Haynes RB. Interventions to enhance medication adherence in chronic medical conditions: a systematic review. Arch Intern Med 2007;167:540-50.

69 Dean AJ, Walters J, Hall A. A systematic review of interventions to enhance medication adherence in children and adolescents with chronic illness. Arch Dis Child 2010;95:717-23.

70 Young K, Duggan L, Franklin P. Effective consulting and history-taking skills for prescribing practice. Br J Nurs 2009;18:1056-61. 